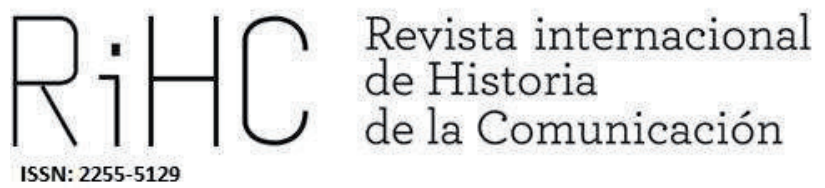

\title{
LOS NIVELES DE LA \\ REPRESENTACIÓN Y EL PERFIL \\ DEL NARRADOR EN EL NO-DO. \\ EL CASO DE CÓRDOBA. \\ SELECCIÓN DE REPORTAJES \\ (1946 - 1951)
}

The levels of representation and the narrator's profile. The case from Córdoba. Selección de reportajes (1946 - 1951)

DOI: http://dx.doi.org/10.12795/RiCH.2021.i17.09

Recibido: 26-2-2021

Aceptado: 9-5-2021

Águeda María Valverde Maestre

Universidad de Granada, España

aguedavalma@correo.ugr.es

ORCID (i) 0000-0002-8362-5019 
Resumen: El NO-DO surge ante la necesidad de crear un noticiario oficial durante la dictadura franquista. Por lo general, estas obras audiovisuales, consideradas como expresiones del patrimonio histórico y audiovisual español, son examinadas con el objeto de analizar fenómenos como el rol de la mujer en la dictadura o las herramientas propagandísticas empleadas. No obstante, este estudio se centra en la dimensión textual del NO-DO, analizando las tipologías del narrador, los puntos de vista y los regímenes de la representación presentes en la recopilación "Córdoba. Selección de reportajes" (19461951), elaborada por Radio Televisión Española (1976). Su finalidad es descubrir nuevos rasgos estructurales del NO-DO. Los resultados de esta investigación aportan nuevas nociones acerca de las particularidades narrativas y discursivas de las cintas, protagonizadas por la ausencia de cambios a lo largo de tres años.

Palabras clave: Patrimonio fílmico, patrimonio histórico, archivo fílmico NO-DO, representación, narrador.

\begin{abstract}
NO-DO was born from the necessity of creating an official newscast during Franco dictatorship. In general, these audiovisual works, considered as expressions of the Spanish historical and audiovisual heritage, are examined in order to analyze phenomenas such as the role of women in the dictatorship or the propaganda's tools used. Nevertheless, this study focuses on the textual dimension of the NO-DO, analyzing the typologies of the narrator, the point of view and the regimes of representation present in the compilation "Córdoba. Selection of reports" (1946-1951), produced by Radio Televisión Española (1976). This purpose tries to discover new structural features of NO-DO. The results of this research provide new notions about the narrative and discursive particularities of the tapes, starring in the absence of changes over three years.
\end{abstract}

Keywords: Audiovisual heritage, historical heritage, film archive NO-DO, representation, narrator.

\title{
Introducción
}

La fascinación del ser humano ante la posibilidad de registrar imágenes en movimiento proviene del siglo XIX, motivada por el desarrollo de los equipos de captación fotográfica. Invenciones como el zootropo, el praxinoscopio y el kinetoscopio "se consideran como los precursores de la cinematografía" (Del Amo-García, 2006: 9). Estos avances inspiran los mecanismos de filmación de los hermanos Lumière. Estas cintas comenzaron a exhibirse en lugares públicos, mostrando a los espectadores desde comedias a acciones cotidianas (Hernández-Velasco, 2015). La aceptación de la audiencia ante estas proyecciones desemboca en el inicio de la industria cinematográfica. Destacan avances como la invención de los géneros cinematográficos (distinguiendo las contribuciones de "Georges Méliès (...), considerado como el padre de la ciencia ficción" (García, 2020), la configuración de espacios específicos para la 
exposición de los filmes (las salas de cines) y la necesidad de recoger obras cinematográficas en dos "soportes físicos: (...) originales y copias" (Del Amo-García, 2006: 10). La naturaleza de estos soportes, compuestos por láminas de plástico y gelatina, es frágil, por lo que precisan de labores de conservación concretas.

Las pérdidas causadas por los conflictos bélicos alcanzan el ámbito cinematográfico. El paso del tiempo, las censuras, la irrupción de periodos de combate y el desinterés por la preservación de bienes materiales finalizan con la concepción del patrimonio. En el siglo XX, la sociedad incorpora el "concepto de valor cultural" (Instituto Andaluz del Patrimonio Histórico, 2007: 1). La intención de conservar los objetos, bienes, testimonios y valores sociales, artísticos, culturales e históricos queda recogida en documentos como la Carta de Atenas (1931) o el Convenio de Haya (1954). La Convención sobre la protección del patrimonio cultural, mundial y natural (1972) clasifica los elementos reconocidos como patrimonio en tres grupos: monumentos, conjuntos y lugares. Las obras audiovisuales pertenecen al apartado de monumentos.

En este contexto, España desarrolla la Ley 16/1985, de 25 de junio, del Patrimonio Histórico Español. Su finalidad es asegurar la custodia, la defensa y el acceso público de los bienes culturales objetos del patrimonio. Asimismo, las comunidades autónomas españolas formulan normativas complementarias y se funda la primera filmoteca española, la Filmoteca Nacional, en 1953, "un organismo encargado de la preservación del patrimonio cinematográfico español" (Ministerio de Cultura y Deporte, 2021).

\section{El archivo fílmico NO-DO}

La aparición de los medios de comunicación en España es paulatina. En el ámbito de la prensa escrita, España es la propulsora de uno de los primeros periódicos de periodicidad diaria en el contexto europeo. El 1 de febrero de 1758 nace el Diario de Madrid, distinguido por la implicación de Mariano Nipho, considerado como el primer periodista oficial español. Alrededor de cien años después, el 14 de mayo de 1896, el francés Alexandre Promio proyecta la primera obra audiovisual en territorio español, marcando el inicio de la industria cinematográfica en el país. No obstante, la televisión se instaura en España "más bien tarde, como culminación de un complejo proceso de ajuste en el imaginario del poder político (...). Esta decisión no puede explicarse por el argumento de las carencias presupuestarias, sino como resultado de una política de medios muy concreta" (Ibáñez, 2001: 48). El 29 de septiembre de 1942, época enmarcada por la dictadura del General Francisco Franco, se funda el NO-DO (acrónimo de Noticiarios y Documentales) (Radio Televisión Española, 1969). Entre otras causas, la ausencia ( $y$, de forma posterior, la escasa evolución de la televisión frente a la prensa escrita y la cinematografía) propicia que dichas obras audiovisuales se emitan, de 
manera obligatoria, en las salas de cine españolas (tanto en la península como en las "colonias" y en las "posesiones" (Radio Televisión Española, 1969). El NO-DO surge ante la necesidad de crear un noticiario oficial y tiene como referentes los noticieros Luce, UFA y FOX. La información presentada en los reportajes NO-DO recuerda "a una revista de prensa rosa (...). Es un documento casi atemporal y en ocasiones no tiene rigor histórico, (...) eludía la información" (Melendo-Cruz, 2021).

La estructura de estas obras audiovisuales se caracteriza por la presentación de un mosaico de noticias de una duración media de diez minutos. Con el fin de sorprender al espectador, recurren al tratamiento de temáticas diversas (distinguiendo los sucesos políticos y las crónicas deportivas) y a la falta de un esquema para exhibir los contenidos. Destaca la presencia del narrador, interpretado por hombres relevantes en el panorama audiovisual. El discurso narrativo utiliza la retórica con el propósito de mostrar amabilidad, falsa veracidad y compromiso con la información. A nivel formal, resalta la composición fotográfica.

Pese a que el archivo fílmico NO-DO no emerge como un instrumento de propaganda política, estos documentos recogen, de forma implícita, la ideología franquista. De hecho, "a partir del 1 de enero de 1943, queda prohibida la edición de cualquier otro tipo de noticiario documental o cinematográfico" (Gómez, 1995). Según Joaquín Soriano, el primer director del NO-DO, la misión principal de estas cintas es similar a los intereses de la dictadura de Francisco Franco "hacer llegar a España a los últimos confines del mundo. Pondrá en ridículo a los cretinos que nos difaman, aumentando la atracción que por nosotros sienten quienes por cultos y honrados nos tienen" (Soriano, 1942, en Gómez, 1995). En referencia al séptimo arte, "la censura de la dictadura franquista (...) abortaba cualquier proyecto que pudiera contravenir las normas dictadas desde el estado" (Navarrete-Galiano, 2015: 25). Por el contrario, los medios de comunicación "supervivientes" se consideran como "prensa (...) adscrita al régimen" (García-Gómez, 2017).

La crisis del archivo fílmico NO-DO comienza en 1962. En 1975, se elimina la obligatoriedad de divulgar estos metrajes en las salas de cine. Debido a su estrecha relación con el gobierno franquista y su falta de adaptación a la industria televisiva, el NO-DO finaliza su actividad en 1981. Por medio de la Orden de 20 de mayo de 1980 y los debates del gobierno socialista español (1982-1996) acerca de la responsabilidad de conservar y custodiar este noticiario, se determina que el Ministerio de Cultura y Deporte es el encargado de salvaguardar dichos reportajes en las filmotecas, y se autoriza su venta, en exclusiva, a Radio Televisión Española.

El objetivo principal de esta investigación es analizar los reportajes del NO-DO desde el punto de vista de la narrativa audiovisual, con el fin de describir las particularidades textuales de estos documentos. La muestra analizada está formada por cuatro de las nueve piezas independientes que conforman el vídeo Córdoba. Selección de reportajes 
(1946-1951). Consiste en una recopilación de grabaciones que narran sucesos de distinta índole acontecidos en Córdoba, elaborada en 1976 y alojada en la plataforma digital A la carta, de Radio Televisión Española. La observación de dichas piezas sirve para constatar la evolución del tratamiento de la información y de la configuración de la representación en obras audiovisuales con una temática común durante tres años.

Este estudio plantea dos hipótesis, relacionadas con el análisis de los tres niveles de la representación (Casetti y Di Chio, 1990) y el examen de los elementos narrativos de una obra audiovisual (Sánchez-Noriega, 2005, 2015, 2018). En primer lugar, la puesta en escena, la puesta en cuadro y la puesta en serie cambian con el transcurso del tiempo, acorde a la experiencia del medio y a los avances tecnológicos. Por el contrario, las singularidades del narrador permanecen estáticas, convirtiéndose en un "símbolo de identidad" del NO-DO.

Las fuentes principales de esta investigación son, en relación al marco teórico y al estado de la cuestión, Del Amo-García (2006), García-García (2016), Ibáñez (2001), MelendoCruz (2018, 2021), Rodríguez-Cabrillo (2016) y Sánchez-Biosca y Tranche (2006). En referencia a la metodología, destacan Casetti y Di Chio (1990) y Sánchez-Noriega (2005, 2015, 2018).

\section{Marco teórico}

\subsection{Estudios acerca del NO-DO}

Durante la dictadura del General Francisco Franco se impuso la divulgación de las obras audiovisuales relacionadas con el NO-DO en las salas de cine pertenecientes al territorio español. Desde la calidad de estas piezas hasta los ideales transmitidos a través de la narración influyeron en la configuración sociocultural de los ciudadanos españoles. Por estos motivos, entre otras cuestiones, la bibliografía acerca del archivo fílmico NO-DO y la repercusión de estas cintas en España son numerosas.

Por un lado, Sánchez-Biosca y Tranche (2006) abordan el contexto cultural, económico, ideológico, jurídico, social y político del NO-DO "a través del conjunto de su producción (Noticiario, revista semanal titulada "Imágenes" y documentales)" (Sánchez-Biosca y Tranche, 2006: 1). Los autores corroboran que el NO-DO evoluciona hacia un instrumento de propaganda política, una herramienta de divulgación subjetiva y un mecanismo para el entretenimiento popular. Esta investigación profundiza en las cuatro décadas de actividad de este organismo y "plantea un análisis minucioso de la elección 
y construcción de las noticias, su disposición en el seno del Noticiario, su estilo de lenguaje y la representatividad de sus imágenes respecto a la sociedad española de su tiempo" (Sánchez-Biosca y Tranche, 2006: 1), concluyendo con la importancia del NODO para la construcción del imaginario tanto nacional como extranjero acerca de España, el establecimiento de los principios de la dictadura franquista en la ciudadanía española y el legado tanto cultural como histórico del país.

Al igual que ocurre con el estudio de Sánchez-Biosca y Tranche (2006), las investigaciones acerca del archivo fílmico NO-DO se caracterizan por la puesta en valor del patrimonio y legado histórico de estas piezas y por el análisis de la dimensión narrativa de las mismas. Melendo-Cruz (2018) estudia la realidad económica, social y política de la dictadura franquista por medio de la transcripción de los monólogos y diálogos de reportajes acerca de moda femenina, con el fin de exponer los ideales tanto machistas como patriarcales de la época. "El camino de la sumisión de la mujer estaba trazado. Este fue uno de los objetivos principales de la sección femenina. Lo que se esperaba del sexo débil" (Melendo-Cruz, 2018: 72). La autora demuestra "cómo, a través de un elemento como la moda, y valiéndose de distintos recursos visibles (...), los reporteros de NO-DO desplazan la atención del espectador hacia aspectos que se encaminan a la formación y el adoctrinamiento" (Melendo-Cruz, 2018: 77). El uso de la oratoria, unida a un discurso subliminal y a la fascinación de la audiencia permitieron al gobierno y a la Iglesia católica convertir estas obras audiovisuales en un "instrumento de propaganda" (Melendo-Cruz, 2018: 61).

En otro orden, el estudio de Rodríguez-Cabrillo (2016) examina el contexto histórico, la temática, la sinopsis, los recursos expresivos y las estrategias comunicativas del archivo fílmico NO-DO, combinando el visionado de reportajes representativos con la descripción de los valores del noticiario elaborada por Sánchez-Biosca y Tranche (2001). El análisis de Rodríguez-Cabrillo (2016) se distingue por combinar la investigación de los recursos discursivos y de los elementos narrativos aplicados en este medio de comunicación. El autor distingue "la voz en off como estrategia para complementar las imágenes que se muestran" (Rodríguez-Cabrillo, 2016: 46). De acuerdo a las reflexiones de Melendo-Cruz $(2018,2021)$, entre otros autores, afirma que "respecto al rigor periodístico del NO-DO (...) existe una noción difusa sobre el concepto actualidad" (Rodríguez-Cabrillo, 2016: 72). En relación al ámbito formal, "se observa que muchas de las noticias que toma están relacionadas con el ocio el entretenimiento en las que se usa un montaje narrativo" (Rodríguez-Cabrillo, 2016: 72).

García-García (2016) reflexiona sobre el legado del archivo fílmico NO-DO. El arquitecto profundiza en la evolución de las fábricas del Plan Badajoz. La intención de este análisis de contenido es "explorar los resultados con fuentes documentales mixtas: gráficas y escritas por un lado y cinematográficas por otro. Con la idea del posible cruce informativo y enriquecimiento mutuo" (García-García, 2016: 585). La investigación 
subraya la escasa información recopilada a través del visionado de estos reportajes, pese a "la importancia de los medios de comunicación (...) en el primer franquismo" (DelgadoIdarreta, 2019: 12). El autor argumenta "que (...) al avanzar la investigación fue quedando de manifiesto que las fuentes (...) tradicionales, reúnen una información mucho más detallada y completa (...) que las de tipo cinematográfico" (García-García, 2016: 585). No obstante, reconoce "que los documentales de la época transmiten el entusiasmo oficial de su propaganda de forma única y emotiva, con sus textos, su música y la expresividad de sus imágenes" (García-García, 2016: 585).

En relación al patrimonio cultural y social, Llull-Peñalba (2005) argumenta la importancia de estudiar "las distintas acepciones del patrimonio: como propiedad en herencia, como selección histórica, como sedimento de la parcela cultural, (...) conformador de la identidad social y (...) modelo de referencia” (Llull-Peñalba, 2005: 179). La observación de las manifestaciones culturales y sociales permite "la valoración de determinados bienes culturales como signos de identidad y referentes de una civilización" (LlullPeñalba, 2005: 180). Por consiguiente, el examen de la representación en el archivo fílmico NO-DO expone la evolución de los recursos tanto narrativos como formales en el ámbito de la comunicación audiovisual española.

La presente investigación comparte aspectos clave con los estudios referenciados. El archivo fílmico NO-DO es relevante para la investigación de la industria audiovisual, la observación de los medios de comunicación como un mecanismo para la difusión de ideología política, y la preservación del patrimonio tanto histórico como fílmico, contribuyendo a la conservación del conocimiento científico-técnico. No obstante, pese al interés de dicho archivo fílmico tanto por sí mismo como por su legado, esta investigación sitúa como objeto de estudio principal las particularidades narrativas y las singularidades discursivas de estas obras audiovisuales. De igual manera, los estudios mencionados no tratan los regímenes de la representación en el archivo fílmico NO-DO. Este artículo formula la siguiente cuestión: ¿cuál es la evolución de la puesta en serie, la puesta en cuadro, la puesta en escena y la tipología del narrador? En este caso, este enfoque para el análisis tanto formal como de contenido es inusual, dadas su especificidad y la dificultad ante la imposición de límites, frente a la reflexión sobre la ideología de estas cintas.

\subsection{Desde el documental al reportaje y la noticia}

John Grierson (1926) emplea el término documentary por primera vez en un testimonio para el The New York Times: "siendo una recopilación sobre la vida de un joven polinesio y su familia (...) tiene un valor documental". Oxford English Dictionary registra tanto dicho término como su significado original en 1989, refiriéndose a una película, obra literaria o representación artística basada en hechos reales o realista, con el objetivo de enseñar o de registrar. En España, la Real Academia Española incluye el vocablo 
documental en 1956, recogiendo dos acepciones: "que se funda en documentos, o se refiere a ellos" (Real Academia Española, 1956) y “dicho de una película cinematográfica o de un programa televisivo. Que representa, con carácter informativo o didáctico, hechos, escenas, experimentos, etcétera, tomados de la realidad" (Real Academia Española, 1956).

Aunque ambas descripciones son similares, los límites del documental no están definidos, desde su concepción como un género cinematográfico hasta su acercamiento con la ficción, un fenómeno como caracterizado por la subordinación de la realidad ante la imaginación. Autores como Godard (1960) y Zunzunegui (1995), afirman que "la mejor ficción tiende al documental, y viceversa" (Godard, 1960) o "que (...) "todo "film narrativo' documenta una ficción, pero todo 'film documental' ficcionaliza una realidad preexistente" (Zunzunegui, 1995: 56). El documental y la ficción tienen dos nexos: ambos recursos se transmiten a través de la narración de un relato y consiguen apelar a la reflexión y a las emociones del espectador.

El reportaje es un género periodístico derivado del imaginario del documental, ya que, "prescindiendo de la ficción, también en el reportaje hay una realidad cuya reconstrucción sólo depende del buen criterio de un narrador, que si en este caso no inventa, a menudo tiene que imaginar para deducir" (Parratt, 2003: 11). Asimismo, al igual que ocurre con el documental, "numerosos estudiosos han elaborado sus propias definiciones, sin que ninguna de ellas pueda considerarse del todo precisa" (Parratt, 2003: 33). En síntesis, el reportaje aborda hechos actuales, sean o no noticiosos, caracterizados por una temporalidad y una estructura variable, de autor.

En relación al acrónimo NO-DO (compuesto por la unión de Noticiarios y Documentales), la noticia es un género periodístico "cuyo propósito (...) es dar a conocer los hechos de interés colectivo (...). Es un relato veraz y breve de hechos novedosos e interesantes" siendo "el menos subjetivo de todos los géneros", ya que se limita a "relatar lo sucedido" (Torres-Casiano, 2019: 23). Según Llanos (1993), los principios de la noticia son la actualidad, la proximidad, la prominencia, la trascendencia, la novedad, el interés humano, la reactividad, la recreatividad y el misterio (Torres-Casiano, 2019: 27-28).

Por ende, las obras audiovisuales del NO-DO son un híbrido entre el reportaje y la noticia, dadas su arbitrariedad para elegir aquellos sucesos susceptibles a ser filmados, que se convierten en un referente popular u objeto del interés ciudadano, la duración indeterminada de las piezas, la estructura indefinida para la presentación de los hechos, la subjetividad implícita en la narración, y la elección de España como una temática y situación geográfica común. 


\section{Metodología}

\subsection{Metodología aplicada al estudio de los recursos discursivos: los tres ejes de la representación}

La metodología escogida es de carácter cualitativo, a causa de su idoneidad para el estudio de disciplinas relacionadas con las Ciencias Sociales, las Artes y las Humanidades. Esta investigación combina una de las categorías del método propuesto por SánchezNoriega $(2005,2015,2018)$ referente al estudio de los recursos narrativos de una obra audiovisual, y el modelo de análisis de los tres ejes de la representación formulado por Casetti y Di Chio (1990).

La metodología de Casetti y Di Chio (1990) recopila las aportaciones precedentes acerca de la narrativa audiovisual y elabora distintas estructuras intuitivas para el estudio de fenómenos audiovisuales concretos. A pesar de que las investigaciones acerca del panorama audiovisual continúan enunciando nuevas herramientas para el análisis de las obras audiovisuales, las pautas para examinar un filme de Casetti y Di Chio (1990) siguen vigentes y se emplean en múltiples estudios científicos.

Casetti y Di Chio (1990) tratan la ambigüedad del término representación en el ámbito cinematográfico. "El término representación (...) viene a significar, por un lado, la puesta en marcha de una reproducción, la predisposición de un relato, y por otro, la reproducción y el relato mismos" (Casetti y Di Chio, 1990: 121). Por consiguiente, el esquema propuesto relaciona la representación con una metodología de carácter "estructural y categorial" (Casetti y Di Chio, 1990: 122).

Los autores diferencian tres niveles de análisis en una obra audiovisual. En primer lugar, definen la puesta en escena. Este ámbito está relacionado con el contenido de la imagen: “objetos, personas, paisajes, gestos, palabras, situaciones, psicología, complicidad, reclamos, etc., son todos los elementos que dan consistencia y espesor a la pantalla" (Casetti y Di Chio, 1990: 127). La información referente a estos apartados se clasifica en cuatro categorías: "los informantes, los indicios, los motivos y los temas" (Casetti y Di Chio, 1990: 129).

A continuación, definen la puesta en cuadro. Relaciona los elementos "que dan cuerpo al universo representado en el film (objetos, individuos, paisajes, situaciones, etc.) y la manera en que este universo se representa concretamente en pantalla" (Casetti y Di Chio, 1990: 131-132). Este ámbito se centra en la composición fotográfica de la cinta, en cómo se presenta el contenido. A modo de ejemplo, se refieren a los elementos aparecidos en pantalla como dependientes (lo representado no tiene relación con la 
acción representada) o independientes ("cuando (...) la imagen subrayará el acto de asunción del contenido, las decisiones (...) con que se apropia de objetos, personas, ambientes, etc., con el resultado de sacar a la luz la propia naturaleza de las imágenes" (Casetti y Di Chio, 1990: 134), y estables (“la asunción o presentación de contenidos se define de una vez por todas y luego se mantiene constantemente") (Casetti y Di Chio, 1990: 134) o variables (la presentación de contenidos es heterogénea). Dada la complejidad y las numerosas tipologías existentes en el ámbito de la composición fotográfica, los autores no enuncian otras categorías.

Por último, esta metodología especifica en qué consiste la puesta en serie. En este nivel, los fotogramas se analizan de forma grupal, profundizando en la relación entre el contenido y el montaje. Casetti y Di Chio (1990) proponen otros modelos focalizados en la edición de una obra audiovisual. Sin embargo, en este apartado, estudian la disposición de las transiciones de forma general. Determinan si existe, o no, nexo entre dos planos, si esta transición se produce por condensación ("fluido, homogéneo, fácilmente reconocible") (Casetti y Di Chio, 1990: 136) o por articulación (una modalidad caótica, propia del cine moderno, relacionada con "fenómenos como el décadrage o el falso raccord") (Casetti y Di Chio, 1990: 136).

Nivel

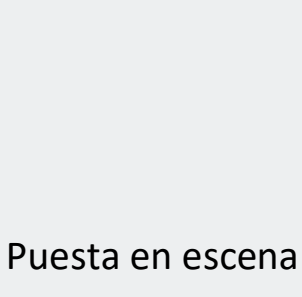

Puesta en escena

Puesta en cuadro

Puesta en serie
Determinación del...

Contenido

\begin{tabular}{|c|c|c|c|}
\hline & & \multirow{3}{*}{ Ejemplaridad } & Arquetipos \\
\hline & & & Claves \\
\hline & & & Figuras \\
\hline \multirow[t]{2}{*}{ Puesta en cuadro } & Modalidad & \multirow{2}{*}{\multicolumn{2}{|c|}{$\begin{array}{c}\text { Dependencia / Independencia } \\
\text { Estabilidad / Variabilidad }\end{array}$}} \\
\hline & & & \\
\hline \multirow[t]{3}{*}{ Puesta en serie } & Nexo & Nexo & Condensación \\
\hline & & & Articulación \\
\hline & & No nexo & Fragmentación \\
\hline
\end{tabular}

Como se menciona en apartados anteriores, la muestra escogida para la fase de análisis se compone de cuatro de las nueve piezas que conforman Córdoba. Selección de reportajes (1946-1951). Esta compilación, elaborada por Radio Televisión Española (1976), permite estudiar textos fílmicos enmarcados en una localización común. En estas cintas, la ubicación funciona como un eje temático, ya que la narración relaciona los 
sucesos con las características del lugar en el que ocurren. La selección de obras audiovisuales con un tema similar evita las diferencias formales existentes entre películas con estilos, formatos, audiencias o ambientaciones dispares.

En referencia al tamaño de la muestra, se seleccionan cuatro piezas, en lugar de nueve, con el objetivo de observar, de manera detallada, la información referente a los tres ejes de la representación y a la tipología del narrador. Por otro lado, la elección de las cintas Visita del Jefe del Estado, Francisco Franco Bahamonde a Córdoba provincia (1946), Corridas de la feria de Córdoba capital. Actuación de 'El Choni', Pepín Martín Vázquez, Parrita, Antonio Bienvenida y Luis Mata (1948), Córdoba en fiestas (1948) y Romería en Almodóvar del Río (Córdoba provincia). Traslado procesional de la Virgen de Fátima. Festival Taurino con asistencia de Rafael Gómez 'El Gallo' (1949), está motivada por tres factores. En primer lugar, estos vídeos abordan sucesos diferentes entre sí, pero son de interés para el gobierno de la época (las visitas del dictador a municipios españoles, las corridas de toros, las festividades típicas y la importancia de la religión). En segundo lugar, su ubicación en el tiempo permite observar la evolución del NO-DO a lo largo de tres años. Por último, la autora de la presente investigación considera estas cuatro obras audiovisuales de mayor relevancia frente a las cinco restantes. De esta manera, esta investigación aporta un nuevo enfoque, debido a que, hasta la fecha, los estudios acerca del NO-DO se enmarcan en las características generales de sus obras audiovisuales (destacando su función propagandística o su impacto, tanto en la época en la que fueron divulgadas como en su posterior legado).

\subsection{Metodología aplicada al estudio de los recursos narrativos: enunciación y punto de vista}

Según Sánchez-Noriega (2015), el narrador es un elemento imprescindible para contar una historia, "es quien produce la acción narrativa, las técnicas y estrategias (...). Se postula en la medida en que es responsable de los componentes, tanto de la historia como del discurso (...). Ningún relato se cuenta a sí mismo" (Sánchez-Noriega, 2015: 47). La imagen "adquiere subjetividad" por medio de la narración (Sánchez-Noriega, 2015: 47). El autor establece dos clasificaciones relacionadas con la tipología del narrador, utilizando como referencia las cuatro posibilidades del tiempo de narración de Genette.

El narrador posterior cuenta un relato pasado, acontecido. Por otro lado, la "narración es anterior a los hechos narrados, como en las anticipaciones, premoniciones, etc" (Sánchez-Noriega, 2015: 48). La narración simultánea o contemporánea transcurre en el presente. Por último, la narración intercalada aparece en contadas ocasiones. En este caso, "no siempre resulta fácil distinguir el tiempo de la acción y el de su narración, ya que ambas están muy próximas" (Sánchez-Noriega, 2015:48). 
La implicación del narrador en el relato se clasifica en tres niveles. El narrador de primer orden o intradiegético participa en la historia. Entre otras acepciones, se encuentra la definición del narrador homodiegético. Este sujeto colabora en el documento fílmico, transcurrido en el presente. El narrador de segundo orden, metadiegético, heterodiegético o testigo tiene presencia en la obra. Sin embargo, "no actúa, es decir, es responsable de un segundo relato o narración metadiegética, (...) una narración dentro de la narración" (Sánchez-Noriega, 2015: 48). Por el contrario, el narrador persona o extradiegético resulta de "la ausencia del narrador en la diégesis (...), está fuera de la historia (...) y, por lo tanto, es exterior a los sucesos que narra. También se habla de narrador impersonal" (Sánchez-Noriega, 2015: 45).

Con el fin de realizar un análisis completo, el autor considera el punto de vista o modo narrativo. Este perfil examina las funciones del narrador como "perceptor de la historia" (Sánchez-Noriega, 2015: 48).

Sánchez-Noriega (2015) considera tres tipos de puntos de vista, vinculados a los enunciados de Genette. La focalización cero o el relato no focalizado se corresponde con la definición del narrador omnisciente "que sabe más que el personaje" (SánchezNoriega, 2015: 49). La focalización interna o subjetiva equivale al narrador en primera persona. "Puede ser fija o variable, en función de que cambie a lo largo del relato y haya uno o más personajes (...), y múltiple, cuando hay más de un personaje desde el que se cuentan los mismos sucesos" (Sánchez-Noriega, 2015: 49). La focalización externa u objetiva se refiere al narrador extradiegético. Genette (1989) define como paralipsis a la omisión de información voluntaria por parte del narrador. En la paralipsis, "el narrador dice más de lo que debe, sobrepasando lo que por el modo de focalización conoce" (Sánchez-Noriega, 2015: 49).

\section{Análisis}

\subsection{Análisis de los tres ejes de la representación}

La pieza Córdoba. Selección de reportajes recopila nueve noticias, filmadas entre 1946 y 1951. Con el fin de realizar un análisis completo, comparativo y sin repeticiones, esta investigación estudia cuatro reportajes.

La primera cinta, Visita del Jefe del Estado, Francisco Franco Bahamonde a Córdoba provincia (1946), tiene una duración de un minuto y treinta segundos. En referencia a la metodología de Casetti y Di Chio (1990) y a la puesta en escena, los informantes son "los elementos que definen en su literalidad todo cuanto se pone en escena: la edad, la 
constitución física, el carácter de un personaje; el género, la cualidad, la forma de una acción, etc" (Casetti y Di Chio, 1990: 127). En esta noticia existen tres grupos de informantes. En primer lugar, destacan los habitantes de Córdoba: hombres y mujeres de mediana edad. A juzgar por sus ropajes, pertenecen a una clase social media. Los cordobeses acuden, en masa, a los espacios por los que pasea el caudillo. Arrojan flores y persiguen el coche oficial del gobernante, en señal de agradecimiento. A continuación, las imágenes y la voz del narrador subrayan la presencia de mujeres jóvenes, "vestidas a la andaluza". Las niñas escoltan el automóvil del dictador, montadas a caballo. Durante su camino a pie, dicho dictador aparece rodeado de militares condecorados y uniformados. El locutor menciona a la mujer de Francisco Franco como acompañante del mandatario en esta travesía. Sin embargo, no figura en las imágenes. Por último, Franco, con cincuenta y tres años, recorre los emplazamientos cordobeses andando y en un automóvil amplio y distinguido. El mandatario, uniformado y con condecoraciones, saluda, en una ocasión, a las masas. Sonríe al recibir la lluvia de pétalos. A pesar de su escasa presencia en la noticia, es el protagonista del reportaje.

Los indicios son "los presupuestos de una acción, el lado oculto de un carácter, el significado de una atmósfera, etc" (Casetti y Di Chio, 127). El comportamiento de los informantes y el relato del narrador retratan al dictador como una figura de poder, querida y reconocida por los habitantes de Córdoba. Los militares y cuerpos de seguridad se sitúan como protectores del caudillo. Los policías acordonan la zona para detener el paso de la multitud. La travesía a pie del dictador es custodiada por los militares. A su vez, las motocicletas y coches de estos organismos rodean el automóvil del gobernante.

Los temas "sirven para definir el núcleo principal de la trama (...): indican la unidad de contenido en torno a la que se organiza el texto (...); en torno a lo que gira el film o lo pone (...) en evidencia" (Casetti y Di Chio, 1990: 128). A colación de los motivos, "indican (...) el espesor y las posibles directrices del mundo representado. En la práctica, son las unidades de contenido que se van repitiendo a lo largo de todo el texto" (Casetti y Di Chio, 1990: 128). Como se expresa en apartados anteriores, la noticia gira entorno a la visita de Franco a la capital cordobesa. Las imágenes pretenden demostrar la admiración de los habitantes de Córdoba hacia el dictador y ensalzar la bondad del caudillo, agradecido ante el recibimiento.

La puesta en cuadro de esta noticia refuerza los conceptos vistos en la puesta en escena. En relación a la captación de las imágenes, la ubicación de la acción parece difusa. El encuadre se centra en el retrato de las acciones ciudadanas, sinónimas de devoción hacia el dictador. El ideal de admiración popular prevalece ante el interés por mostrar la localización espacio-temporal de los hechos. A modo de demostración, se exponen dos ejemplos. Con el fin de contextualizar la narración, en el primer plano del reportaje se exhibe el Puente Romano, un monumento simbólico cordobés. La angulación de la 
cámara es normal. Sin embargo, en los encuadres posteriores, las imágenes se captan desde una angulación picada. De esta forma, la multitud ocupa la imagen. Por el contrario, para filmar al caudillo, se eligen planos cerrados y cercanos, con el fin de enfatizar su expresión facial en la lluvia de flores, o sus gestos, al saludar desde la ventana del coche oficial.

La puesta en serie está compuesta por nexos de condensación y articulación. Las asociaciones por proximidad están protagonizadas por la repetición de encuadres acerca de la acogida de los cordobeses. La inserción de planos cortos del caudillo, centrados en su disposición y júbilo, conforman las asociaciones por transitividad. Las tomas están unidas mediante cortes, con el fin de mostrar una edición o montaje natural, carente de manipulación. Estos elementos articulan "un universo compacto, fluido, homogéneo y fácilmente reconocible" (Casetti y Di Chio, 1990: 136). Este esquema refuerza las premisas vistas en la puesta en escena y la puesta en cuadro. La exposición y reiteración de estos componentes en esta noticia y en las consecutivas fomentan la concepción de devoción ante el dictador entre la población española.

La segunda cinta, Corridas de la feria de Córdoba capital. Actuación de 'El Choni', Pepín Martín Vázquez, Parrita, Antonio Bienvenida y Luis Mata (1948), tiene una duración de dos minutos y cuarenta y tres segundos.

Los informantes principales de este reportaje son los toreros mencionados en el título de la pieza. Las corridas de toros se convirtieron en una actividad de ocio nacional y una celebración típica por mandato del "dictador Francisco Franco, declarado aficionado a los toros" (Rábago-García, 2017). Por consiguiente, los reportajes de carácter deportivo del archivo fílmico NO-DO destacan la importancia de esta celebración y del fútbol. Los toreros eran personajes públicos reconocidos. La vestimenta de los toreros se caracteriza por el uso de manoletinas, medias, montera, capote y traje de luces. Las imágenes manifiestan los logros obtenidos por los toreros en las corridas transcurridas en Córdoba. Los informantes secundarios son el público de estas celebraciones, conformado por hombres y mujeres de mediana y avanzada edad, de clase social alta. Vestidos de gala, acuden, en masa, a este evento. Celebran los triunfos de los toreros, levantándose y aplaudiendo. Este espectáculo ocurre en las plazas de toros cordobesas. Estos emplazamientos están relacionados tanto con la puesta en escena como con la puesta en cuadro del reportaje. De nuevo, la importancia de la localización prevalece ante el tema, la victoria y la elegancia demostrada por los toreros en el ruedo cordobés, y el motivo, el retrato de España como una nación unida, festiva, de tradiciones, sin pobreza. Los indicios refuerzan estos supuestos. Los gestos cómplices del grupo y la presentación de jugadas exitosas por los toreros, así como la mención de la incursión de dos aficionados al ruedo generan una atmósfera cómica, amable y alegre, presentando tanto a las corridas de toros como a España como lugares felices. 
El reportaje comienza con la presentación de un plano general de la feria de Córdoba y un plano detalle de una placa distintiva, con el texto "Plaza de Toros" en mayúscula. La sucesión de imágenes intercala las exhibiciones protagonizadas por "El Choni", Pepín Martín Vázquez, Parrita, Antonio Bienvenida y Luis Mata, con las reacciones de la audiencia. Con el fin de identificar a los toreros, el narrador menciona sus apodos tras su aparición. La función principal de la composición fotográfica es captar las acciones acontecidas. Por ello, los planos protagonizados por las hazañas de los toreros y la presencia de la población en el evento son de carácter general, tanto abiertos como cerrados. Por el contrario, la aceptación y el disfrute del público se filma mediante planos medios cortos y primeros planos de sus rostros. La angulación de las escenas es normal y no aporta información relevante. Sin embargo, en esta noticia existe una evolución técnica respecto a la cinta anterior. Aparecen los movimientos de cámara, como los paneos y los zoom - in.

La puesta en serie de este reportaje repite los conceptos vistos con anterioridad. Las asociaciones de proximidad se caracterizan por la repetición de tomas acerca de las coreografías de los toreros. A su vez, la inclusión de planos protagonizados por el público de este evento presenta las asociaciones por transitividad. De nuevo, el montaje busca tanto demostrar la veracidad de los acontecimientos como reforzar las ideas expuestas en la puesta en escena y la puesta en cuadro.

La tercera cinta, Córdoba en fiestas (1948) tiene una duración de cuatro minutos y treinta y nueve segundos. En esta noticia coexisten seis grupos de informantes. Los eventos protagonistas de esta festividad es la exhibición de ganado y los concursos de parejas a caballo y amazonas atabilladas a la andaluza. De nuevo, los gustos, las aficiones y los intereses del caudillo son los ejes principales del reportaje. Los animales encuadrados son equinos, dada la fascinación del dictador ante estos seres y la creciente relevancia del corcel andaluz en el panorama europeo. Según Fernández (2003), "Franco fue muy aficionado a montar a caballo, tanto que en un desfile de la Victoria, celebrado en el Paseo de la Castellana, revistó las tropas sobre un vistoso corcel". Dichos animales de diversos tamaños y pelajes, desfilan o permanecen en orden en jaulas, obedeciendo a los cuidadores y retratando al hombre como un ser poderoso y dominante ante no humano.

A continuación, destaca la importancia del estatus social. El narrador subraya la procedencia gitana de los comerciantes de ganado. Este grupo, compuesto por jóvenes y adultos masculinos, de clase social baja y media, reconocibles por sus sombreros cordobeses, ocupan menos de un minuto en pantalla. Por el contrario, el retrato de hombres de mediana y avanzada edad, trajeados y pertenecientes a la élite social adquieren una posición distinguida tanto en la feria como en el reportaje. La aparición de los militares y las alabanzas hacia su yeguada simboliza la trascendencia de estas figuras, adscritas al régimen. A su vez, es de interés analizar el tratamiento hacia los 
participantes de los concursos de parejas a caballo y de amazonas atabilladas a la andaluza. El narrador remarca la profesionalidad de los jueces, pertenecientes a la Comisión de Ferias, pero omite el nombre y la procedencia de la amazona ganadora del evento. Por último, se describen las tradiciones andaluzas. En las celebraciones detalladas (aprender a bailar, las sevillanas y la batalla de las flores) aparecen personas de diversas edades y clases sociales. La intención de este grupo es informar acerca de las festividades andaluzas y españolas. Los informantes y los indicios mostrados en este epígrafe están conectados con el mensaje implícito o motivo de este reportaje: la presentación de Córdoba, Andalucía y España como lugares ideales para el turismo internacional. Estas localizaciones aparecen retratadas como emplazamientos óptimos para disfrutar del ocio, de un comercio privilegiado y de la tradición, sello distintivo de la Península Ibérica. A su vez, estas concepciones se transmiten en el ámbito nacional, junto al tema: las festividades y tradiciones cordobesas, una ciudad distintiva.

La puesta en cuadro está protagonizada por los planos generales. Este tipo de encuadre permite a la audiencia televisiva contemplar las acciones transcurridas, con el fin de subrayar la importancia de los eventos expuestos con anterioridad. Los planos cortos encuadran elementos de interés, como los corceles o los pasos ejecutados en las sevillanas. Su objetivo es realzar los arquetipos, figuras, claves e indicios de esta noticia. Dada la importancia de Córdoba como destino turístico, existe un mayor número de imágenes destinadas a contextualizar la narración (en comparación con las piezas descritas con anterioridad).

La puesta en serie repite el esquema de nexos y asociaciones. Un ejemplo de asociación por proximidad es la sucesión de tomas acerca de las sevillanas. Las asociaciones por transitividad responden a la presentación de diferentes temáticas, como la batalla de las flores o los concursos equinos, entre otras, enmarcadas en la feria de Córdoba.

La cuarta pieza analizada corresponde a la penúltima noticia realizada por el archivo fílmico NO-DO acerca de Córdoba, Romería en Almodóvar del Río (Córdoba provincia). Traslado procesional de la Virgen de Fátima. Festival Taurino con asistencia de Rafael Gómez 'El Gallo' (1949) tiene una duración de cuatro minutos.

Este relato es un ejemplo de la evolución estética de las imágenes religiosas. La virgen de Fátima yace en un lecho de hojas de palma y claveles. En esta época, estas esculturas destacan por su acompañamiento floral, su tamaño y sus ropajes de terciopelo, bordados con oro y encaje. El acompañamiento del paso demuestra la importancia de la Iglesia católica y la tradición religiosa ligada tanto a España como a Andalucía. Los carros de madera, decorados con hojas de palma, están ocupados por mujeres jóvenes y mediana edad. Por el contrario, los hombres jóvenes y de mediana edad se sitúan a los extremos de la procesión, montados a caballo. A pie, aparecen las mujeres y hombres de edad avanzada junto a los infantes. Estos grupos de personas visten con trajes típicos 
andaluces, tales como vestidos de gitana o trajes cordobeses. Las últimas imágenes acerca de este evento recuerdan al enfoque de la multitud visto en la primera pieza.

Las particularidades vistas en el reportaje taurino anterior se repiten en esta sección. Rafael Gómez "El Gallo", torero y celebridad española, es el protagonista de la exhibición taurina, dada su experiencia en el sector. El hombre de avanzada edad, vestido con un traje cordobés blanco, actúa amable ante los lanceros sin identificar, conversando con ellos y observando el espectáculo desde un asiento privilegiado. En este caso, la audiencia adquiere un segundo plano. Por otro lado, los lanceros ejecutan al toro sobre un corcel, dotando al equino de nobleza y superioridad frente al vacuno.

Los indicios y motivos presentes en esta cinta son similares a los comentados en las creaciones anteriores, subrayando la importancia de la tauromaquia y del arquetipo del torero, el retrato de Córdoba, Andalucía y España como destinos turísticos ideales, el respeto por la tradición, el valor de las fiestas nacionales, la distinción del caballo andaluz, la distinción de la figura masculina y la calidad de vida española. Sin embargo, en esta ocasión se añade la concepción del respeto y la admiración hacia las personas de edad avanzada, un rasgo cultural significativo.

El tema de este reportaje son las festividades religiosas y taurinas celebradas en Almodóvar del Río. Con el transcurso de las noticias, las localizaciones adquieren mayor relevancia a causa del interés por exponer ante la audiencia nacional e internacional las virtudes de las localidades españolas. Por el contrario, la evolución de la puesta en cuadro respecto a los reportajes anteriores es inexistente. Los encuadres predominantes son los planos medios cortos y los planos generales. El montaje está compuesto por tomas variadas. Sin embargo, el esquema utilizado es repetitivo. Los movimientos de cámara, las angulaciones y la composición fotográfica mantienen las características vistas en noticias anteriores.

A su vez, la puesta en serie repite las asociaciones y los nexos descritos. Por ejemplo, las asociaciones por proximidad ocurren con la repetición de planos de los carros decorados con hojas de palma. En ocasiones, las tomas se construyen por medio de la ampliación del plano anterior. En el caso de las asociaciones por transitividad, destaca la inserción de planos acerca de la corrida de toros, intercalados con las reacciones de Rafael Gómez "El Gallo". Las transiciones empleadas son cortes, reforzando la concepción de veracidad expuesta.

\subsection{Análisis de la tipología del narrador y el punto de vista}

Las categorías del narrador y los puntos de vista enunciados por Sánchez-Noriega (2005, 2015,2018 ) se manifiestan, de forma similar en los reportajes analizados. En la primera 
cinta, Visita del Jefe del Estado, Francisco Franco Bahamonde a Córdoba provincia (1946), el narrador es extradiegético.

La creación de una noticia o un reportaje implica tres fases: preproducción, producción y postproducción. Dada la naturaleza de estas obras audiovisuales, el narrador es posterior. Las cintas resultantes relatan un suceso pasado. Sin embargo, destaca la combinación de tiempos verbales en pasado y en presente y el uso de formas impersonales.

El punto de vista está condicionado por la tipología extradiegética. La focalización del relato es externa u objetiva ${ }^{1}$. La narración de los archivos fílmicos NO-DO se caracteriza por la omisión de información relevante para la presentación del relato periodístico. Esta pieza carece de datos fundamentales, como el número estimado de asistentes al evento, la fecha, el motivo de la visita del caudillo o el recorrido realizado por el dictador entre otros factores. Como se detalla en epígrafes posteriores, estas obras audiovisuales muestran un imaginario de España impreciso y sesgado, acorde a las preferencias del gobierno de la época. No obstante, el tratamiento de los tres ejes de la representación y las características del narrador exhiben los sucesos como si pertenecieran a una fuente de información rigurosa y comprometida

El punto de vista y las tipologías del narrador presentes en los siguientes tres reportajes replican estas características. Con el transcurso de los años, el narrador incluye en el relato adjetivos y adverbios. Cabe destacar que, pese a que el discurso implementa juicios de valor y comentarios subjetivos (por ejemplo, se habla acerca de la belleza de la mujer) la aplicación de la oratoria, la repetición de valores, la satisfacción obtenida ante la presencia ciudadana en las noticias y la percepción del narrador como una figura culta y prestigiosa enmascaran esta opinión, dando la falsa apariencia de que se trata de una exposición veraz, rigurosa y objetiva.

\section{Discusión de los resultados}

Los resultados obtenidos tras analizar los recursos discursivos y los recursos narrativos presentes en cuatro de las nueve piezas de la recopilación la recopilación Córdoba. Selección de reportajes (1946-1951) permiten constatar la evolución de la representación y del perfil del narrador (en relación con una temática específica) en tres años del NO-DO. La información obtenida a colación de la metodología de Casetti y Di

1 En referencia a las categorías formuladas por Sánchez-Noriega $(2005,2015,2018)$, el tipo de focalización de las piezas mencionadas es externa u objetiva. No obstante, que éste sea el apelativo de esta clasificación no significa que la información que transmiten dichas piezas destaque por su objetividad o veracidad. 
Chio (1990) confirma que existe una clara relación entre estas noticias o reportajes y las disposiciones gubernamentales. Los informantes partícipes en los reportajes examinados responden a los arquetipos, las claves y las figuras de importancia para el régimen. La aparición de los ciudadanos en los medios de comunicación fascina a la audiencia. Este hecho, unido a la divulgación de los eventos locales, la revalorización de los bienes culturales y a la relación implícita entre el gobierno y la información, construyen el imaginario de una dictadura comprometida con los intereses de la población y una nación tanto unida como devota. Asimismo, destaca el tratamiento de los gustos y las aficiones del dictador como temáticas predilectas. En este periódico, "lo noticioso" está subordinado al interés del gobierno, en lugar de al saber de la población. Los indicios y los motivos vistos en estas piezas remiten a los roles impuestos por la dictadura. Las obras analizadas manifiestan la repercusión de la tauromaquia, la importancia del deporte, el rol de la mujer, la presentación de Córdoba, Andalucía y España como destinos turísticos paradisíacos, el respeto hacia las personas de avanzada edad o veteranos de profesión, el valor de la tradición y la diversidad de costumbres propias, la calidad ecuestre, la admiración popular hacia el caudillo, el poder de las fuerzas de seguridad y de los militares, la transcendencia de la religión cristiana y la Iglesia católica, y la presentación de Andalucía y España como naciones unidas, festivas y libres de pobreza.

La puesta en cuadro de las noticias analizadas manifiesta cambios leves. Los operadores de cámara combinan el uso de planos generales, con el fin de contextualizar las acciones acontecidas, y con el empleo de planos medios y primeros planos, dedicados a describir las cualidades de un sujeto $u$ objeto. Las angulaciones refuerzan connotaciones (por ejemplo, la aplicación del ángulo picado en las tomas destinadas a filmar a los habitantes de Córdoba en la visita del caudillo elimina los elementos relacionados con el lugar y enfatiza la presencia de la multitud. A su vez, el uso de ángulos contrapicados para la filmación de los militares asistentes a la exhibición de ganado refuerza su rol autoritario). El movimiento de cámara otorga dinamismo a la imagen. Por último, la ausencia de transiciones decorativas busca emular el compromiso del NO-DO con la información. En resumen, el dominio de la composición fotográfica ayuda a representar los valores comentados en epígrafes anteriores. Con el fin de reiterar estos conceptos, la puesta en serie aplica asociaciones por proximidad y transitividad, confirmando la aparición de nexos de condensación y aparición.

La selección de reportajes examinada corrobora los rasgos estructurales expuestos en las investigaciones mencionadas en el marco teórico. El deporte y la política son géneros de especial interés para el noticiario. A su vez, dada la ausencia de indicadores temporales, las cuatro piezas parecen transcurrir en tiempos similares. Sin embargo, estas noticias acontecen a lo largo de tres años diferentes. El nivel espacial es de suma importancia, ya que, como se menciona en epígrafes anteriores, la ubicación del relato adquiere relevancia y funciona como una temática común. En este caso, la misión 
principal de estas piezas es ensalzar las virtudes de Córdoba, Andalucía y España para complacer a la ciudadanía y presentar una imagen positiva a países extranjeros.

El análisis encuadrado en los recursos narrativos enunciado por Sánchez-Noriega (2008, 2015,2018 ) demuestra que la tipología del narrador y los puntos de vista implícitos en estos documentos fílmicos no evolucionan, convirtiéndose en un símbolo de identidad del NO-DO. Pese a que el narrador es posterior, dada la imposibilidad de captar y emitir imágenes en movimiento de forma simultánea, la narración incluye tiempos verbales presentes. La finalidad de esta característica es dotar de actualidad a la cinta. Asimismo, la inclusión de formas no personales pretende imitar objetividad y veracidad. Estas peculiaridades, combinadas con el uso de un lenguaje comprensible pero no vulgar, amable y cómico, la repetición de ideales y conceptos y la presencia de locutores de prestigio, como Joaquín Ramos, David Cubedo o Matías Prats, conforman una oratoria sólida y convincente, capaz de transmitir a la audiencia los ideales deseados.

\section{Conclusiones}

Este artículo cumple su objetivo principal, aportando información precisa acerca de los tres ejes de la representación y las particularidades del narrador implícitas en el archivo fílmico NO-DO, comentadas en epígrafes anteriores. En otro orden, la primera hipótesis planteada por esta investigación no es correcta, debido a que las características de los tres niveles de la representación se repiten, de forma constante, pese al paso del tiempo. Este hecho corrobora, de nuevo, el interés por representar los valores impuestos por la ideología franquista y la configuración de estas piezas como obras audiovisuales atemporales, desprovistas de los principios del lenguaje periodístico. Por medio de la selección de una temática específica (en este caso, la provincia de Córdoba como ubicación geográfica y premisa protagonista), los resultados no se han sido alterados por variables extrañas relacionadas con el estilo, los formatos, las ambientaciones y las audiencias. No obstante, tomando como referencia los estudios vistos en el marco teórico, es posible afirmar que las singularidades vistas en esta muestra, caracterizada por su especificidad, son aplicables al resto de cintas del NO-DO.

Estos reportajes replican las técnicas publicitarias aplicadas por regímenes políticos con principios similares, como el nacionalismo alemán. Este motivo, unido al retrato favorable del caudillo imposibilitan la desvinculación entre estos documentos audiovisuales y la dictadura, lo cual desencadena en la crisis y en la posterior desaparición del NO-DO. 
Por otro lado, tal y como indica la segunda hipótesis, las peculiaridades y los puntos de vista del narrador permanecen estáticos, convirtiéndose en una huella distintiva de estos filmes.

En definitiva, este estudio, caracterizado por la exploración de los tres ejes de la representación, sirve como complemento a los resultados obtenidos en estudios anteriores, enfocados en el análisis de contenido y el montaje cinematográfico aplicados en el NO-DO. Se destaca la intención de transmitir la bondad y las aficiones del caudillo, España como un país alegre, divertido y feliz, las mujeres como un ente secundario, donde su única importancia reside en su belleza, la aceptación de los ciudadanos ante la situación política y la sensación de que el tiempo permanece estático.

Por último, este estudio propone continuar con el examen de fenómenos audiovisuales no analizados hasta la fecha, con el propósito de profundizar en los códigos formales y narrativos presentes en estos noticiarios, como la postproducción sonora y la intertextualidad. El archivo fílmico NO-DO no solo recoge un hito en la historia audiovisual de España. Su existencia implica la conservación del patrimonio español y su legado repercute en la construcción cultural, social, política y económica del país, así como en los inicios de la televisión.

\section{Referencias bibliográficas}

ALVARADO JÓDAR, A. (2015): La postcensura en el cine documental de la transición española [Tesis Doctoral, Universidad de Málaga]. https://riuma.uma.es/xmlui/bitstream/handle/10630/11195/TD_Alvarado_Jodar .pdf?sequence $=1$

ALVARADO JÓDAR, A. Y BARQUERO ARTÉS, C. (2013): “Un despertar revulsivo: prácticas colaborativas en el documental sobre el 15-M" en Fonseca, Journal of Communication, no2, 2013, pp. 304-324.

AgenCIA eStATAL (1985) Ley 16/1985, de 25 de junio, del Patrimonio Histórico Español. España: Boletín Oficial del Estado. Disponible en Internet: https://www.boe.es/buscar/act.php?id=BOE-A-1985-12534

CARRerA díAZ, G. (2009): "Atlas del Patrimonio Inmaterial de Andalucía. Puntos de partida, objetivos y criterios técnicos y metodológicos" en Revista ph, nำ71, 2009, pp.18-41.

CASETTI, F. Y DI CHIO, F. (1990): Cómo analizar un film. Barcelona: Paidós. 
CORDOBA, SELECCIÓN DE REPORTAJES (1949-1951) en Radio Televisión Española (1-11976).

FRANCO HA MUERTO (1975) en Radio Televisión Española (1-1-1976).

FLORIDO TRUJILLO, G. (2013): “El patrimonio territorial en el plan de ordenación del territorio de Andalucía: Indefiniciones y dificultades para un conocimiento preciso" en Boletín de la Asociación de Geógrafos Españoles, №23, 2012, pp. 173201.

GARCÍA CASADO, P. Y ALBERICH PASCUAL, J. (2015): “El estándar DCl en las filmotecas. El proceso de transición al sistema digital en la actividad filmotecaria contemporánea (2010-2014)" en Revista Española de Documentación Científica, nำ38, 2015, pp.1-13.

- (2014a): “Filmotecas en la encrucijada. Función y expansión de la actividad filmotecaria en el nuevo escenario digital" en El profesional de la información, no23, pp. 59-64.

- (2014b): “Origen y desarrollo de la actividad filmotecaria en España. Implementación de la singularidad del mapa filmotecario español ante el nuevo contexto digital (1954-2012)" en Historia y Comunicación Social, no19, 2014, pp.279-289.

GARCÍA GARCÍA, R. (2016a): El legado de la industria: archivos, bibliotecas, fototecas de empresa. Fábricas y memoria, Gijón, INCUNA.

- (2016b). "Fábricas del Plan Badajoz en las referencias bibliográficas y en el NODO”, en Álvarez Aceres, M.A. (coordinador), El legado de la industria: archivos, bibliotecas, fototecas de empresa. Fábricas de memoria, Gijón, INCUNA, pp. 585592.

- (2020): "Méliès, el mago que inventó el cine de ciencia ficción" en La claqueta de la Historia. Disponible en Internet (1-6-2020): https://blogs.20minutos.es/laclaqueta-de-la-historia/2020/06/01/melies-el-mago-que-invento-el-cine-deciencia-ficcion/

GODARD, J.L. (Dir.) IMPÉRIA FILMS, SOCIETÉ NATIONALE DE CINEMATOGRAPHIE Y LES PRODUCTIONS GEORGES DE BEAUREGARD (Prod.) (1960). À bout de souffle [película].

GÓMEZ, R.G. (1995): “RTVE edita 50, años de historia de España filmados por NoDo”. EI País. Disponible en Internet (18-12-1995): https://elpais.com/diario/1995/12/18/radiotv/819241201 850215.html 
DEL AMO GARCÍA, A. (2006): "La conservación cultural del patrimonio cinematográfico y la investigación científica" en ARBOR Ciencia, Pensamiento y Cultura, no717, 2006, pp. 9-16.

DELGADO IDARRETA, J.M. (2019): Propaganda y medios de comunicación en el primer franquismo (1936-1953), Universidad de La Rioja, Servicio de Publicaciones.

FERNÁNDEZ, C. (2003): "HEMEROTECA. Franco asiste al concurso hípico en San Sebastián". La Voz de Galicia. Disponible en Internet (5-8-2003): https://www.lavozdegalicia.es/noticia/vigo/2003/08/05/hemeroteca-francoasiste-concurso-hipico-san-sebastian/0003_1887788.htm

FERNÁNDEZ GUERRA, V. Y ALONSO RUIZ DE ERENTZUN, E. (2017): “La última vez que te escribí. Contemporizando el concepto de documento en la cultura de la imagen documental: correspondencias fílmicas y diarios filmados" en Revista Signa, no26, pp. 877-892.

HERNÁNDEZ VELASCO, I. (2015): “Así empezó todo”. El Mundo. Disponible en Internet (16-3-2015):

https://www.elmundo.es/cultura/2015/03/16/5505bb4d22601d574f8b4579.ht $\mathrm{ml}$

IBÁÑEZ, J.C. (2001): "Televisión y cambio social en la España de los años 50: Apuntes sobre el proceso de legitimación del medio televisivo en la dictadura de Franco" en Secuencias, no13, 2001, pp. 48-67.

INSTITUTO ANDALUZ DEL PATRIMONIO HISTÓRICO (2021a) Patrimonio cultural. España: Conserjería de Cultura, Junta de Andalucía. Disponible en Internet: https://www.juntadeandalucia.es/temas/culturaocio/andalucia/patrimonio.html

INSTITUTO ANDALUZ DEL PATRIMONIO HISTÓRICO (2021b) Qué es el patrimonio cultural. España: Conserjería de Cultura, Junta de Andalucía. Disponible en Internet: https://www.iaph.es/export/sites/default/galerias/patrimoniocultural/documentos/gestion-informacion/que_es_patrimonio_cultural.pdf

LLULL PEÑALBA, J. (2005): "Evolución del concepto de la significación social del patrimonio cultural", en Arte, Individuo y Sociedad, no17, 2005, pp.175-204.

MARTínEZ, A. (2016): “El día en que el cine llegó a España” en Cadena Ser. Disponible en Internet (21-5-2016): https://cadenaser.com/programa/2016/05/13/sucedio_una_noche/1463155831 _767354.html 
MELENDO CRUZ, A. (2021): "Filmoteca: justificación, interés y razón de ser". Conferencia en Máster en Cinematografía, Universidad de Córdoba. Instituto de Estudios de Postgrado [online]. 11 de diciembre de 2020.

- (2018): “Vestidos para después de una guerra. La mujer y la moda en el Archivo Histórico NO-DO durante el periodo autárquico", en Antropología Experimental, no18, 2018, pp. 64-78.

MÉNDEZ RODRÍGUEZ, L., PLAZA ORELLANA, R. Y ZOIDO NARANJO, A. (2010): Viaje a un Oriente europeo. Patrimonio y turismo en Andalucía (1800-1929), Bailén, Fundación Pública Andaluza (Centro de Estudios Andaluces).

MINISTERIO DE CULTURA Y DEPORTE (2021a) Archivo histórico de NODO. España: Ministerio de Cultura y Deporte, Gobierno de España. Disponible en Internet: http://www.culturaydeporte.gob.es/cultura/areas/cine/mc/fe/fondoscinematog raficos/documentacion-fc-

archivo/archivodocumental/archivohistoriconodo.html

- (2021b) Qué es la Filmoteca. España: Ministerio de Cultura y Deporte, Gobierno de España. Disponible en Internet: https://www.culturaydeporte.gob.es/cultura/areas/cine/mc/fe/presentacion/qu e-es-la-

filmoteca.html\#: :text=La\%20Filmoteca\%20Espa\%C3\%B1ola\%20es\%20un,cinem atogr\%C3\%A1fico\%20y5\%20promover\%20su\%20conocimiento.

NAVARRETE GALIANO, R. (2015): Galdós y la censura del cine español, en FILMHISTORIA Online, no1, 2015, pp. 35-44.

NODO: Una historia próxima. Programa especial 50 años. TVE 1993 (23-5-2015).

PARRATT, S.F. (2003): Introducción al reportaje: antecedentes, actualidad y perspectivas, Universidad de Santiago de Compostela, Servicio de Publicaciones e Intercambio Científico.

PRADO GARCÍA, J.M. Y DEL AMO GARCÍA, A. (2005): “Proyectos y experiencias. Creación de acceso al patrimonio fílmico. Colecciones temáticas y especiales de la Filmoteca Española" en Revista ph, no56, 2005, pp.114-115.

REAL ACADEMIA ESPAÑOLA (2021a) Documental. España: Real Academia Española. Disponible en Internet: https://dle.rae.es/documental?m=form

REAL ACADEMIA ESPAÑOLA (2021b) Reportaje. España: Real Academia Española. Disponible en Internet: https://dle.rae.es/reportaje?m=form

REDACCIÓN CORDÓPOLIS. (2020): “La filmoteca ofrece dos programas para acceder desde casa al patrimonio fílmico Andaluz" en Cordópolis. Disponible en Internet 
(21-3-2020): https://cordopolis.eldiario.es/cultura/filmoteca-ofrece-programasacceder-casa-patrimonio-cinematografico-andaluz_1_7023960.html

REDACCIÓN EL PAÍS. (2017): “La fiesta nacional, vista por El Roto” en El País. Disponible en Internet

(21-4-2017): https://elpais.com/elpais/2017/04/21/album/1492782001_358265.html\#foto_g al_10

REPISO CABALLERO, R., TORRES SALINAS, D. Y DELGADO LÓPEZ-COZAR, E. (2011): "Análisis bibliométrico de redes sociales en tesis doctorales españolas sobre televisión (1976/2007)", en Comunicar: Revista científica iberoamericana de comunicación y educación, no37, 2011, pp.151-159.

RODRÍGUEZ CABRILLO, C. (2016): “El cine como instrumento de propaganda: EI NO-DO" en Repositorio de la Universidad de Valladolid, 2015-2016, pp. 9-76.

ROSILLO RUBIO, L. (2014): “El patrimonio urbano y natural andaluz a través del cine. La evolución visual del paisaje cultural como crítica histórico-artística" en Erph_revista electrónica del patrimonio histórico, no14, 2014, pp. 205-225.

RUIZ ORTEGA, J.L. (2004): "Patrimonio y desarrollo local en Andalucía" en Boletín de la A.G.E., $\mathrm{n} \div 28,2004, \mathrm{pp} .101-114$.

SÁNCHEZ NORIEGA, J.L. (2005): Historia del Cine: Teorías, estéticas, géneros. Madrid: Alianza.

- (2019): Historia del Cine: Teorías, estéticas, géneros. Madrid: Alianza.

STREINGRESS, G. (2003): "El flamenco como patrimonio cultural o una construcción artificial más de la identidad andaluza" en Anduli, Revista Andaluza de Ciencias Sociales, no1, 2003, pp. 43-63.

TORRES CASIANO, R.E. (2019): Identificamos las características de la noticia [Trabajo de Suficiencia Profesional, Universidad Nacional de Trujillo]. https://dspace.unitru.edu.pe/bitstream/handle/UNITRU/14593/TORRES\%20CASI ANO\%20RENZO\%20ESTEBAN.pdf?sequence $=1$ \&isAllowed $=y$

ZUNZUNEGUI, S. (1995): "Imagen, documental, ficción", en Revista de Ciencias de la Información, no2, pp. 53-62. 